\title{
A Product Model to Capture and Reuse Ecodesign Knowledge
}

\author{
Miriam Kozemjakin da Silva, Emmanuel Guyot, Sébastien Remy, and Tatiana Reyes \\ Université de Technologie de Troyes, Troyes, France \\ $\{$ kozemjam, emmanuel.guyot, sebastien.remy, \\ tatiana.reyes_carrillo\}@utt.fr
}

\begin{abstract}
Ecodesign is the improvement of the environmental performance of products or services throughout their whole lifecycle. Because there is less design freedom in the late stages of the design process, it is assumed that if the environmental constraint is introduced early, the designers would develop a product that would have a better environmental performance. Thus, case-based reasoning is proposed as a strategy to incorporate ecodesign early in the design process.

The paper shows the investigation about the different possibilities of capturing information during the product development process. The idealized model to capture information called Core Product Model extension for environmental evaluation $\left(\mathrm{CPMe}^{3}\right)$ is presented. This formal model would allow capturing the data from the whole product's lifecycle with a link to the environmental evaluation.
\end{abstract}

Keywords: Ecodesign, knowledge capture, lifecycle thinking, product model.

\section{Introduction}

The environmental performance of products is emerging as a new constraint for designers. This is a complex constraint due to multiple indicators (e.g. global warming, toxicity and water depletion) and to the need of a lifecycle view, i.e. a perspective of consequences of the design decisions. There is then, an effort to make ecodesign tools that would help designers to improve the environmental performance of products.

Life cycle assessment (LCA) is one of the most used environmental evaluation tools. This tool requires an advanced stage of design to evaluate the product with reduced uncertainty. The problem is that, as seen in figure 1 , as more advanced in design, fewer are the possibilities of the designer to influence the product's environmental performance [1]. This implies that the designer has access to the product's environmental evaluation when it is too late to make significant changes to the product. To summarize, "the goal during the design process is to learn as much about the evolving product as early as possible in the design process because during early phases changes are least expensive" [2]. 


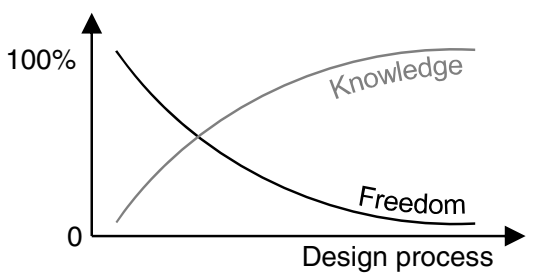

Fig. 1. Design paradox. The designer's freedom to make changes to the product versus the knowledge about the design problem (adapted from [2]).

There are several approaches that have been developed to act in early stages of design, for example, guidelines and checklists [3]. This approaches present generic conclusions and need constant updates to guide decision making in a good direction. Hence, the authors approach is to improve efficiency of ecodesign, by helping engineering designers to make better-informed decisions, learning from past designed products.

\subsection{Literature Review}

Research in cases-reuse for ecodesign (i.e. the estimation of environmental impact of a new product, early in design, based on products with similar characteristics) has been done by Jeong et al. [4]. The authors introduced a case-based reasoning (CBR) with environmental evaluation purposes. CBR is an artificial intelligence technique that imitates the human behavior for problem solving, i.e. finding similar cases in the past and adapting it for solving a new problem [5]. The case is, here, stored within a database structured using the product model FBSe (function-behavior-structureenvironment). After, similarity is analyzed between the new product and the products' cases stored in a casebase; finally analogy is used to estimate the impact of the new product.

Moreover, Devanathan [6] conduct LCA into teardown benchmarked products giving an impact to the bill of materials (BOM). Then, the authors relate the BOM to product's functions. Next, those functions are related to customer and environmental requirements (QFD). The redesign is then focused on the functions impacts to support conceptual design and concept selection. Here, the called "working knowledge model" is also centred on the product. The structure FBS is found again, enriched by Objective, Constraint, Attributes and Requirements.

Another approach dependent on the analysis of past designs, presented by Dick et al. [7] and Ostad-Ahmad-Ghorabi et al. [8], is parametric ecodesign. The idea is to "establish a coupling between functional requirements (FR) or design parameters (DP) that product developers have at hand in early design phases and the environmental impact (EI) of the product" [7].

Finally, Bohm et al. [9] have used a design repository of environmental evaluated products to automatically generate virtual concepts. Once more, the repository is structured around product entities, mainly the BOM. 


\subsection{Case-reuse in Ecodesign}

The approach proposed by the authors is based on the capture of information about the product during its whole lifecycle and the use of it in the next product's generation. In other words, a design process in the form of a decision chain is stored. Analyzing this memory could allow designers to see the cause-effect link, where the cause is the decision and its effect on the environmental impact. Next, if during the development of a new product, a similar set of decisions has to be taken, the designer can look at its consequences throughout the entire life of the previous product. Doing so, the user is able to evaluate the consequences of this same decision on the current product. The designer concludes, then, about the options that should be reconsidered for having less environmental impact in the next product's generation.

The research showed in the literature review share close motivation to this work when enabling designers to compare the product that is being designed to previous products in order to evaluate its environmental impact. Nevertheless, this research aims to go further by addressing the following specifications:

- The lifecycle view aspect. On the form of a network of decisions linked to the environmental impact. Because life cycle view is the heart of ecodesign practice;

- The reasoning behind the decisions of the product development process and the context of the product's design (design rationale). Because design rationale has interesting assets to information reuse: "design rationale can offer designers useful information about how previous designs evolved and the context in which such evolution happened" [10];

- The dependency on the designer's interpretation, meaning that it is out of our interest to replace the designer interpretation by automatic generation of LCA results or automatic generation of design concepts. Because the knowledge reuse can be source of inspiration and reflection [11];

- The capture and retrieval system is adapted to casual users. Because designers and environmental specialists are not computer system experts;

The focus of this paper is on investigating how to capture design information so that it could be reused with ecodesign purposes. In section 2 , based on literature review, the possibilities seen of knowledge capture and reuse techniques are shown and discussed. Section 3 describes the core product model extension for environmental evaluation $\left(\mathrm{CPMe}^{3}\right)$. Finally, discussions and conclusions are addressed in section 4.

\section{Knowledge Reuse Scenarios}

The ability to reuse design information is dependent on capture, representation and retrieval mechanisms. The design information is extracted from the design process. It is widely assumed that design is an unstructured and informal process, which produces many data. These data are included in many types of file formats (e.g. email, reports and conversations). It is also important to understand that neither the mind of the designer, nor the process of design, follows a specific structure or sequence [12]. 


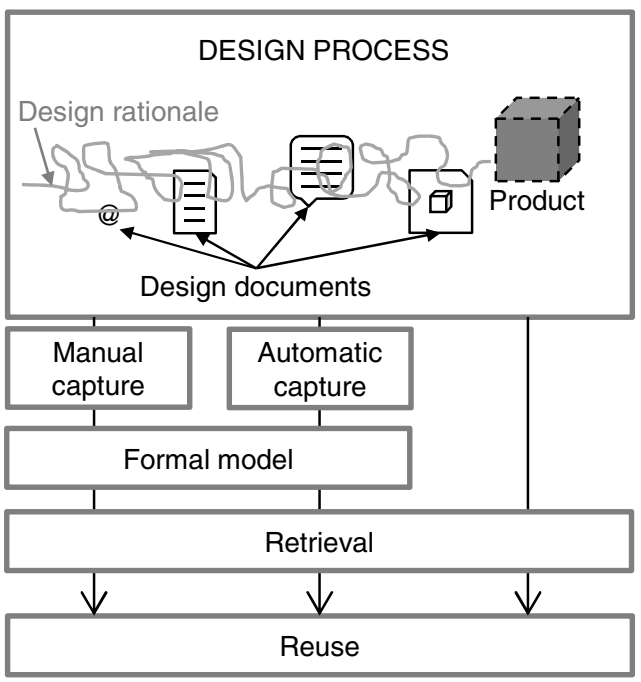

Fig. 2. The knowledge reuse possibilities

From the design process, three scenarios are seen for reusing knowledge, as illustrated in figure 2 . In the first scenario, design information is manually captured and structured to a formal model. In the second one, the information is automatically captured and structured to a formal model. In the third one, the information is retrieved and presented without any treatment.

From the three scenarios presented, only those that require a formal model are going to be considered, because:

- it is less likely that disorganized design information would be reused, it would require a lot of time for reinterpretation;

- $\quad$ the retrieving phase would lose in effectiveness;

- it would imply storing a large amount of data, which would mostly not going to be necessary;

Also, as presented in section 1.1, the related work that have been presented have chosen to use a structure, a product model, as a formal model to capture and store design information.

Next section is about an overview of some technologies for capturing the product development process information.

\subsection{Knowledge Capture}

The mechanisms for capturing the design process, as seen before, are either automatic or manual.

Manual capture means that someone will have to formalize the process by inputting data to some structured format. A product model, for example, is a format that enables structuring the design by centring on product data during the product 
development process. Among all the product models, the widely mentioned Core Product Model from the NIST (National Institute of Standards and Technology) is presented in section 3 .

The main inconvenience of manual capture is the heavy human involvement to interpret and load information into the system. This extra time required from designers is the main reason for the unpopularity of such model-based approach [13].

Therefore, there is a need to develop a mechanism to automate the data capturing process. For instance, technologies for informal knowledge capture are presented by:

- Liang et al. [14], that use text-mining algorithm to process design rationale documentation. The authors assume that design rationale is documented in natural language (text). Then, design rationale points are automatically extracted from the free text: the issue, the solution and the artifact information.

- Habernal et al. [15] use semantic search system with a natural language interface. The authors believe that as modern search engines are approaching the ability to deal with queries expressed in natural language, full support of natural language interfaces seems to be the next step in the development of future systems.

- Ahmed [16] performed an empirical study to identify a visible indexing structure for the reuse of design knowledge that is captured from many formats. The author states that "indexing design knowledge is one method to support the retrieval of knowledge from a system".

These technologies are not exhaustive and the human-computer interaction field is full of promising solutions. Gruber [17] states that intelligent systems can acquire knowledge by being programmed or modeled that way, or by machine learning from data and information in the world (like Google $\AA$ ). The author foresees machines looking for data without being told to and machines learning from us. A more comprehensive review of knowledge representation in product design is done by Chandrasegaran et al. [12].

Summarizing, there is a clear tradeoff between the effort in capturing the design process, the effectiveness of retrieving it and the convenience for reusing it.

Automatic capture of the design process is certainly suitable for reducing user input work. Nevertheless, two main advantages are seen for doing manual capture: first, a formalization that is done manually reduces the expertise required for implementing the knowledge system; second, filling out the formal model acts as a reminder of what kind of information to input. Besides, the impact of knowledge reuse for ecodesign is the main purpose of this research, the means for doing it being a technical issue.

In the following section, an ideal formal product model is proposed. It is a generic model that can be used to structure information-capture in further case-studies, at first manually. It will also provide technical feedback that would help further information system development. 


\section{$3 \quad \mathrm{CPMe}^{3}$ Product Model}

Product model assists product development process. It deals with information representation, capture, exchange and classification in different levels of abstraction. There are many product models available in literature. The NIST (National Institute of Standards and Technology) worked on a product model to capture the full engineering context to support Product lifecycle management (PLM) [18]. Core product model (CPM) is open, non-proprietary, generic, extensible and UML (Unified modeling language) based [19].

The contribution of CPM is on covering the design process information. The main classes of the model, as seen in figure 3, are: Artifact, represents any physical entity in a product (e.g. part and assembly); Feature, artifact's form that has a function; Form, geometry and material; Function, the intended behaviour; Behaviour, how the Form fulfils the Function. Moreover, OAMFeature is a specialisation of Feature, from the Open Assembly Model extension [18], to support the product structure, i.e. the relation between assemblies and parts.

The created extension to support LCA is based on systems thinking, similar to the modelling logic of LCA software Gabi [20] and Umberto [21].

The heart of the model is the link between Flow, Process, ProcessPlan, Product and Artifact (see grey classes on figure 3). The environmental impact is given for a Flow, so the impact of a Process is the sum of the impacts of the Flows. Consequently, the impact of a series of processes (ProcessPlan) is the sum of each Process' impact. Finally, the impact of a Product is the sum of the impacts of the ProcessPlan. The Product then, inherits the classes from CPM by being connected to Artifact.

The other part of the model describes the lifecycle aspects. A Flow is classified by its nature that is specialized in: material goods like Part, Assembly and Consummable\&tools; immaterial goods like Energy or even a Substance (i.e. a single type of matter consisting of uniform units).

The class ProcessPlan can be found in the CPM extension Manufacturing Process Planning Information Model [22]. Nevertheless, the meaning here is wider, it shows the sequence of manufacturing operations and equally the logistics between them. This idea of mixing Processes to tell the history of the product is valid for all the ProcessPlans, for example, we could find Manufacturing in the UseScenario, as a maintenance process or at the EOLscenario (end-of-life) for disassembling the product.

The phases that are only hypothesized, called scenarios can also be described as a sequence of processes. The two phases considered scenarios are use and end-of-life because they take place after-sales and usually companies have less information about them. EOL Process covers the reuse and waste: recycle (waste materials reprocessed into products), energy recovery (waste recover as a combustion fuel or composting) and disposal (landfill or incineration). Finally, Use is related to the consumptions of the product during the use phase, like the disposable coffee filter for a coffee machine. 


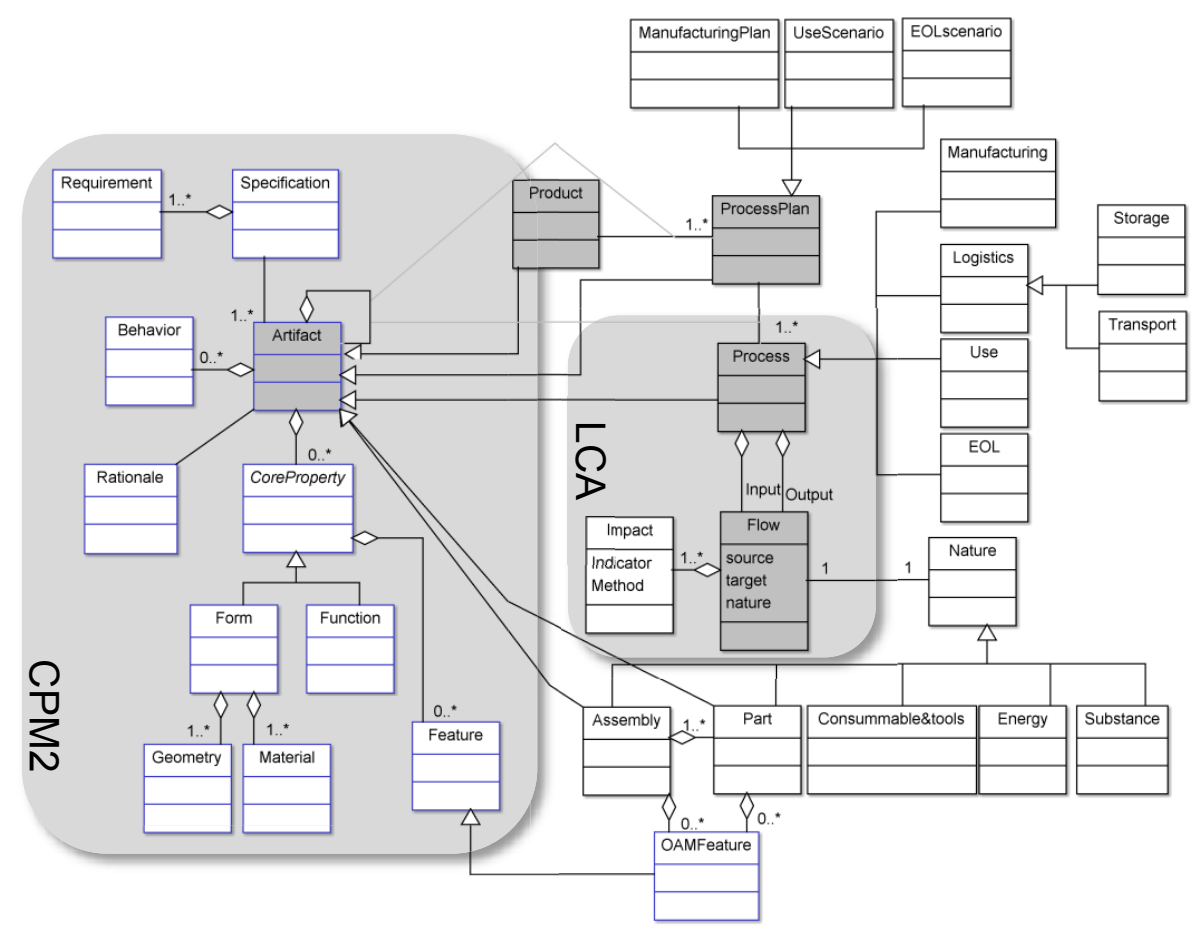

Fig. 3. The $\mathrm{CPMe}^{3}$ extension to support ecodesign

This model is created to support the knowledge capture. Here, this implementation would be done during the lifecycle of the product, allowing environmental evaluation purposes. People involved in the product development process should complete the model as they make decisions.

Thus, the foreseeable implementation of the $\mathrm{CPMe}^{3}$ would be similar to a "topdown" PLM approach. In such an approach, considering the case of a bike, the main Artifact in the model, the Product, is the bike itself. Then, as the design process goes on, the structure of components, Part and Assembly, known as Bill Of Materials (BOM), appear in the model. All the Artifacts are linked to technical data using the CPM product model and linked to Processes of the lifecycle phases.

It is hard to find a product development project with enough documentation to completely instantiate $\mathrm{CPMe}^{3}$. It is also understood that the actual use of PLM in companies does not have the necessary level of data capture and exchange for doing environmental evaluation; and that implementing $\mathrm{CPMe}^{3}$ would depend on a shift on the way things are done in companies. Research has been done towards changing information management so that it would integrate environmental aspects, for instance: by facilitating the interaction of experts [23] and by gathering and making available lifecycle information [24]. $\mathrm{CPMe}^{3}$ is then seen as a generic idealization. 


\section{Conclusion}

As stated in the introduction of this communication, the aim of this research is to capture knowledge during the design process of a product in order to reuse it to improve the environmental impact of new products.

It is assumed, in section 1 and 2, that a formal model is needed to capture and store design information from the design process in order to be able to properly reuse it. The challenge of representing the product development process is approached with an extension of the Core Product Model from the NIST.

$\mathrm{CPMe}^{3}$, if implemented, would structure data from the product development linking it to the environmental evaluation dimension. It would give interoperability between the two dimensions (design and environmental evaluation).

Further research is going to be made on the interface, in which product design process representation is better suited for application in the context of knowledge reuse, for applying a CBR methodology. Nevertheless, the $\mathrm{CPMe}^{3}$ conceptual model contributes as a background on which data is needed to describe the product development process.

Acknowledgements. This research is funded by the Fonds Unique Interministériel (Single Interministerial Fund) and the Champagne-Ardenne Region of France, by the Finather3 project.

\section{References}

1. Dewulf, W.: A pro-active approach to ecodesign: framework and tools (2003)

2. Ullman, D.G.: The mechanical design process. McGraw-Hill (1997)

3. Luttropp, C., Lagerstedt, J.: EcoDesign and the Ten Golden Rules: generic advice for merging environmental aspects into product development. Journal of Cleaner Production 14, 1396-1408 (2006)

4. Jeong, M., Suh, H., Morrison, J.R.: A Framework for Stepwise Life Cycle Assessment during Product Design with Case-Based Reasoning. In: 6th Annual IEEE Conference on Automation Science and Engineering, pp. 118-123 (2010)

5. Watson, I.: Applying case-based reasoning: techniques for enterprise systems. Morgan Kaufmann (1998)

6. Devanathan, S., Koushik, P., Zhao, F., Ramani, K.: Integration of sustainability into early design through working knowledge model and visual tools. In: Proceedings of the 2009 International Manufacturing Science and Engineering Conference, pp. 1-10 (2009)

7. Dick, M., Dewulf, W., Birkhofer, H., Duflou, J.: Estimating the environmental impacts of similar products. In: International Design Conference, Dubrovnik, pp. 1-6 (2004)

8. Ostad-Ahmad-Ghorabi, H.: Parametric ecodesign - An integrative approach for implementing ecodesign into decesive early design stages. In: Proceedings of the 10th International Design Conference, DESIGN 2008, Dubrovnik, Croatia, pp. 1327-1334 (2008)

9. Bohm, M.R., Haapala, K.R., Poppa, K., Stone, R.B., Tumer, I.Y.: Integrating Life Cycle Assessment into the conceptual phase of design using a design repository. Journal of Mechanical Design 132 (2010) 
10. Wang, H., Johnson, A.L., Bracewell, R.H.: The retrieval of structured design rationale for the re-use of design knowledge with an integrated representation. Advanced Engineering Informatics 26, 251-266 (2012)

11. Guo, Y., Peng, Y., Hu, J.: Research on high creative application of case-based reasoning system on engineering design. Computers in Industry 64, 90-103 (2012)

12. Chandrasegaran, S.K., Ramani, K., Sriram, R.D., Horváth, I., Bernard, A., Harik, R.F., Gao, W.: The evolution, challenges, and future of knowledge representation in product design systems. Computer-Aided Design 45, 204-228 (2013)

13. Tang, A., Babar, M.A., Gorton, I., Han, J.: A Survey of the Use and Documentation of Architecture Design Rationale. In: 5th Working IEEE/IFIP Conference on Software Architecture (WICSA 2005), pp. 89-98 (2005)

14. Liang, Y., Liu, Y., Kwong, C.K., Lee, W.B.: Learning the "Whys": Discovering design rationale using text mining - An algorithm perspective. Computer-Aided Design 44, 916930 (2012)

15. Habernal, I., Konopík, M.: SWSNL: Semantic Web Search Using Natural Language. Expert Systems with Applications (2013)

16. Ahmed, S.: Encouraging reuse of design knowledge: a method to index knowledge. Design Studies 26, 565-592 (2005)

17. Gruber, T.R.: Nature, nurture, and knowledge acquisition. International Journal of HumanComputer Studies 71, 191-194 (2013)

18. Sudarsan, R., Fenves, S.J., Sriram, R.D., Wang, F.: A product information modeling framework for product lifecycle management. Computer-Aided Design 37, 1399-1411 (2005)

19. Fenves, S.J., Foufou, S., Bock, C., Sriram, R.D.: CPM2: A Core Model for Product Data. Journal of Computing and Information Science in Engineering 8 (2008)

20. GaBi Software, http: //www.gabi-software.com

21. Umberto: know the flow, http: / / www. umberto. de

22. Marchetta, M.G., Mayer, F., Forradellas, R.Q.: A reference framework following a proactive approach for Product Lifecycle Management. Computers in Industry 62, 672-683 (2011)

23. Rio, M., Reyes, T., Roucoules, L.: Toward proactive (eco)design process: modeling information transformations among designers activities. Journal of Cleaner Production 39, 105$116(2013)$

24. Lejon, E., Lundin, M., Jeppsson, P., Näsström, M.: Integrating Information in Product Development. In: CIRP LCE, Singapore (2013) 